\title{
Participação popular e controle social em saúde: desafios da Estratégia Saúde da Família
}

| 1 Jacks Soratto, ${ }^{2}$ Regina Rigatto Witt, ${ }^{3}$ Eliana Marília Faria |

Resumo: O controle social em saúde no Brasil tem em sua trajetória um processo de luta da sociedade, especialmente a partir dos movimentos sociais organizados. Este artigo trata de um estudo de pesquisa-ação com uma abordagem qualitativa, que teve como objetivo construir um processo de participação popular e controle social em saúde, no território de uma Estratégia Saúde da Família, na região sul do Estado de Santa Catarina. Participaram do estudo a população, usuária do serviço de saúde inserida ou não nos movimentos sociais organizados, juntamente com os trabalhadores de saúde. A coleta de dados consistiu na observação participante e entrevistas. A construção do processo de participação popular e controle social se deu em três momentos: conhecimento situacional, diálogo emancipador e momento "D". Constatou-se que a institucionalização de espaços participativos não garante a participação popular e o controle social em saúde. O estudo apresenta alternativas para a construção deste processo. Neste caso, o diálogo foi o instrumento essencial para a fomentação e busca de outros caminhos para o Sistema Único de Saúde.

> Palavras-chave: participação social; participação cidadã; políticas de controle social; atenção primária em saúde; Sistema Único de Saúde; direito à saúde.

\author{
${ }^{1}$ Mestrando na linha de \\ pesquisa de Políticas e Práticas \\ de Saúde e Enfermagem do \\ Programa de Pós-graduação em \\ Enfermagem da Universidade \\ Federal do Rio Grande do \\ Sul (UFRGS). Pesquisador do \\ Laboratório de Direito Sanitário \\ e Saúde Coletiva (UNESC) e \\ membro do Núcleo de Estudos \\ em Educação, Saúde, Família e \\ Comunidade (UFRGS). Endereço \\ eletrônico: jackssoratto@ \\ hotmail.com. \\ 2 Doutora em Enfermagem \\ pela Universidade de São Paulo \\ (USP). Docente do Programa de \\ Pós-graduação em Enfermagem \\ da Universidade Federal do \\ Rio Grande do Sul (UFRGS). \\ Líder do Núcleo de Estudos \\ em Educação, Saúde, Família e \\ Comunidade e pesquisadora do \\ Núcleo de Estudos sobre Gestão \\ em Enfermagem (UFRGS). \\ Endereço eletrônico: witt@ \\ adufrgs.ufrgs.br. \\ ${ }^{3}$ Doutora em Enfermagem \\ pela Universidade Federal \\ de Santa Catarina (UFSC). \\ Pesquisadora do grupo Práxis: \\ Núcleo de Estudos sobre \\ Trabalho, Cidadania, Saúde e \\ Enfermagem (UFSC). Endereço \\ eletrônico: fariaem@uol.com.br.
}

Recebido em: 31/08/2009. Aprovado em: 03/05/2010. 
O Sistema Único de Saúde (SUS), seus princípios e diretrizes continuam no debate atual, mesmo porque é um sistema que se ancora na perspectiva política e na democracia, tendo no seu arcabouço, pilar importante, a participação popular e controle social, que tem enfrentado muitos desafios por ser uma política de saúde contra-hegemônica. Têm acumulado avanços, mas ainda continua "distante" da proposta da reforma sanitária. Apresenta fragilidades que põem em risco sua legitimidade política e social, especialmente considerando a situação de permanente disputa em relação à saúde como direito, em relação à concepção de saúde e às maneiras de construí-la (BRASIL, 2005).

Essa constatação merece um olhar mais atento, que vai desde a formação da força de trabalho em saúde, ainda voltada para o mercado; da gestão democrática e participativa do SUS em todos os níveis da federação (ficando mais expostas tais fragilidades em nível municipal); a inexistência e ou existência de modo muito incipiente de uma política micro (particularmente em cada município) de Educação Permanente em Saúde, que possa colocar na roda de discussão todos os atores envolvidos na produção do cuidado em saúde.

O foco principal deste estudo foi a identificação de como se processa a construção da participação popular e do controle social em saúde, especificamente, na Unidade Básica de Saúde (UBS) a qual tivesse como modelo de atenção a Estratégia Saúde da Família (ESF). Neste sentido, foi realizado um estudo de pesquisa-ação que teve por objetivo geral construir um processo de participação popular e controle social em saúde, em um território da ESF de um município da região sul de Santa Catarina.

O estudo ${ }^{1}$ teve como ponto inicial conhecer a realidade, criando vínculos com os movimentos sociais organizados, população do bairro no território e com os trabalhadores da ESF, buscando caminhos para a discussão com os mesmos e fomentando o processo de construção da proposta de estudo. As discussões foram sustentadas e fundamentadas sob a ótica da educação problematizadora de Paulo Freire, e de todas as interfaces que cercam tal discussão, tais como: os conceitos de cidadania, participação, direito, cultura, controle social, organização dos serviços de saúde, dentre outras.

O referido estudo partiu dos seguintes pressupostos: (1) grande parte dos profissionais e os gestores não têm conhecimento nem prática para estimular 
a participação e o controle social na saúde; (2) a institucionalização dos conselhos de saúde, por si só, não garante a participação e o controle social na saúde; (3) grande parte da população não possui conhecimento sobre o SUS e, consequentemente, desconhece as formas de reivindicar seu direito à saúde; (4) a participação popular é determinada social, histórica, cultural e politicamente; (5) o controle social em saúde no Brasil tem em sua trajetória um processo de luta da sociedade, especialmente a partir dos movimentos sociais organizados.

\section{Aproximando a problemática}

Ao se olhar a realidade do estudo, depara-se com uma sociedade crítica, porém tímida. De maneira geral, há um sentimento que reclama o todo, principalmente em relação à organização do setor saúde, especialmente na forma como as pessoas são atendidas. É comum se ouvir da população, ao se referir ao atual sistema de saúde, como "algo pobre para pobre e que não funciona”. Em contrapartida, percebe-se que esta mesma população ainda não se despertou para a luta (pelo menos o suficiente) por melhores serviços de saúde.

Há um discurso reclamatório de indignação individual, mas não um de participação coletiva, na detecção, priorização e solução dos problemas cotidianos e da organização dos serviços de saúde. Percebe-se, por outro lado, no interior dos serviços de saúde, o entrave para a participação popular (mesmo com todo o aparato legal). Isso porque abrir a porta e o interior dos serviços de saúde significaria e implicaria compartilhar saberes e poderes.

Vários são os fatores que estão em jogo no controle social, seja por parte da população, dos trabalhadores ou da gestão. Este estudo pretendeu percorrer a trajetória da construção desse processo. Aqui caberiam algumas perguntas: por quais razões a população não se manifesta, não se rebela, frente ao tipo de serviço que lhe é oferecido? Será que os trabalhadores e os gestores estão abertos ao diálogo para consequentemente pulverizar os princípios e diretrizes do SUS?

Uma reposta aproximada para esse marasmo participatório pode estar na maneira como se organiza a produção dos cuidados em saúde, internalizada nos cantos e salas dos serviços de saúde, esperando, apenas, que a "coisa doente" apareça e se medicalize. É um modelo procedimento-centrado em contraposição ao modelo que se almeja, o usuário-centrado. Parece ser esse o grande nó crítico: por um lado, o não-compromisso dos trabalhadores e da gestão com as 
pessoas, tratando-as apenas como uma doença; por outro, as pessoas se sentem incapacitadas diante de uma relação assimétrica, razão pela qual se calam e não se manifestam (MERHY et al., 2004).

Outra explicação para tal silêncio está na forma como se compreende o que seja cidadania, pois a impossibilidade de exercê-la em quaisquer das frentes do cotidiano das pessoas indica e pode explicar relações assimétricas da vida na sociedade, e nas situaçôes em que homem não pode se expressar indicam que o exercício do poder se torna mais visível.

Nas relações entre os profissionais, gestão de saúde e a população, as informações repassadas à população são aquelas que interessam aos serviços de saúde ou aos técnicos. Quase sempre, "são informações normatizadoras, deixando de lado aquelas que interessam à população, agravado pela negação das subjetividades dos envolvidos nas açôes assistenciais (FARIA, 1996 p. 46).

É um saber técnico-científico que nega o saber popular, as subjetividades, seja nos encontros individuais ou coletivos, levando o sujeito adoecido ou não, a não questionar. Em tais circunstâncias, toda e qualquer forma de conhecimento dos sujeitos usuários do SUS é menosprezada, assim apenas tem validade o que está posto, a técnica, o científico.

Os profissionais de saúde, principalmente os médicos, exercem em sua prática os referenciais científicos de modo que "desqualificam [...] o saber popular, entre outros, ao identificá-los como não-científicos e, por isso, ineficazes" (BRASIL, 2005, p. 54).

$\mathrm{Na}$ realidade dos serviços de saúde, há uma grande dificuldade entre os trabalhadores no sentido de mobilizar e incentivar a população, para juntos pensarem e construírem a saúde (a organização da atenção nas ESF, por exemplo). $\mathrm{Na}$ saúde, o tête à tête, a mão dupla, o diálogo, o nós sobrepondo-se ao eu, vai de encontro à prática estabelecida à coisa (a parte corporal doente), e não para e com os sujeitos, como se fosse possível separar o corpo físico do corpo social, o ser humano com sua cultura, suas crenças e valores e sua história.

A negação do sujeito, por si só, resulta na negação de outros direitos, seja o de contar a sua história ou de planejar sua vida e seus cuidados. Muito mais negação se dará quando essa coisa quer tornar-se sujeito (cidadão) e interferir na forma e conteúdo do cuidado em saúde, exercer a sua cidadania, nos momentos terapêuticos individuais ou coletivos, nos conselhos locais e municipais de saúde, 
explicitando que tipo de serviço se quer, de que forma deseja ser cuidado e reivindicando seu direito a saúde.

Já o controle social tem sido exercido de duas formas legais: nos Conselhos de Saúde e nas Conferências de Saúde, sendo que, em ambos os casos, as ações se verificam tanto no plano federal como nos planos estaduais e municipais. No entanto, estas não são as únicas formas de participar da SUS; claro que isso está constituído legalmente, mas os municípios podem criar outros espaços mais descentralizados para a população participar, como: conselhos distritais, ou conselhos locais de saúde (BARROS, 1994, CORTEZ, 2002).

A construção do controle social dentro de um espaço participativo local de saúde torna-se muito importante para a população, pois ampliará ainda mais a descentralização das decisões e a população poderá acompanhar, avaliar e indicar prioridades para as ações de saúde a serem executadas pela respectiva ESF, todavia, não se pode restringir a ele a solução de todos os problemas enfrentados na saúde.

Após a constituição e implementação dos Conselhos e Conferências de Saúde, um espaço que ganhou projeção na relação participativa dos usuários com os setores político-administrativos foi o espaço local (PERNA, 2000). O espaço local (o território) agora pode aparecer na esfera pública, e o indivíduo que habita este local, antes anônimo, surge com identidade e expõe suas questôes sobre a mesa de debate. Porém, mesmo com todos esses canais que podem ser abertos à população, a participação popular nos espaços legais pode sofrer, por um lado, a cooptação, e de outro, a inviabilização política, caso rejeite a participação. A saber, que não são poucos os casos em que as secretarias procuram "criar Conselhos fáceis de manipular, de modo a escapar do Controle Social. Isso só acontece em lugares onde a organização popular não é forte o bastante para fazer cumprir a lei” (BRASIL, 2002, p. 51).

A questão norteadora aqui é a fragilidade da representação, que não possui informação e capacidade argumentativa e, portanto, pouco opina e torna-se manipulável. Cabe refletir que, ao incluir o interesse restrito e imediato dos representantes populares, afastam-se os mesmos da luta pela atenção mais ampla dos representados. Essa questão abre a necessidade de fomentar um processo de participação popular e controle social juntamente a uma política de informação que não seja mera transmissora, muito menos vinculada aos espaços 
1232 institucionalizados municipais e locais de saúde, mas polemizadora de questôes equivale dizer, capaz de problematizar, argumentar e formar opinião.

\section{Caminhos metodológicos}

Diante da proposta que tínhamos para o território referido, adotamos um estudo do tipo pesquisa-ação. Os estudos de pesquisa-ação "intervêm na realidade para transformá-la, a partir dos conhecimentos adquiridos ou produzidos" (TOBAR; YALOUR, 2001, p. 48).

A pesquisa-ação valoriza não só a produção do conhecimento, mas entende que esse processo é emancipador, isto é, "durante a reflexão gerada pela pesquisa (assistência profissional), os sujeitos envolvidos irão desenvolvendo uma consciência crítica sobre o seu cotidiano, ampliando horizontes, de transformação e de intervenção" (DESLANDES; GOMES, 2004, p. 101). Assim, este estudo trilhou uma investigação na direção da transformação de uma realidade, implicada necessariamente na participação dos sujeitos que estão envolvidos.

Nesta pesquisa, tivemos um olhar fundamentado na pedagogia crítica e libertadora (FREIRE, 1987, 1997). A abordagem metodológica para este tipo de estudo é de natureza qualitativa, pois trabalha com o "universo de significados, motivos, aspirações, crenças, valores e atitudes, o que corresponde a um espaço mais profundo das relações, dos processos e dos fenômenos que não podem ser reduzidos à operacionalização de variáveis (MINAYO, 1999, p. 22).

O local do estudo foi um dado território, aqui compreendido não somente como uma área geográfica, mas incluindo toda a complexidade das relações sociais, culturais, econômicas entre outras estabelecidas em seu interior, com aproximadamente 3.400 pessoas, em um município de pequeno porte do sul do estado de Santa Catarina.

Os participantes foram a população da área adstrita, usuária do serviço de saúde, inserida ou não nos movimentos sociais organizados, neste estudo identificados como Espaços Participativos Locais (EPLs), tais como: clube de mães, clube de idosos, pastoral da saúde, pastoral da criança, associação de moradores, associação de pais e professores, juntamente com os trabalhadores da ESF.

O processo de construção da pesquisa ocorreu durante um período de quatro meses. Paralelo a isso, utilizou-se de observação participante (BRANDÃO, 1999) 
e de entrevistas não estruturadas (SILVA; MENEZES, 2001). Esse processo foi mediado por anotações em diário de campo (BECK; HUNGLER; POLIT 2004).

$\mathrm{O}$ percurso da pesquisa foi baseado nas rodas de discussão (individuais e coletivas) a partir de conversas informais na ESF, nas caminhadas e ou através de convites informais e ou escritos para tal fim. As rodas aconteceram tanto no âmbito de cada EPL já instituído, quanto na ESF e no grande grupo aqui descrito como "momento D". Para desencadear estas discussões, foram utilizados processos comunicativos, dialógicos, escritos (slides), e áudio-visual (filmes) numa lógica educacional libertadora.

Para Minayo (1999, p. 129), grupo de discussão

consiste numa técnica de inegável importância para se tratar das questões da saúde sob o ângulo social, porque se presta ao estudo de representações e relações dos diferenciados grupos profissionais da área, dos vários processos de trabalho e também da população.

A observação consistiu no reconhecimento da área geográfica e de abrangência da ESF, em caminhadas e conversas informais com os sujeitos do estudo, quando foram identificados os movimentos sociais organizados (EPL).

Já as entrevistas foram feitas buscando-se identificar as convergências nos discursos dos sujeitos do estudo a um dado tema. Foram entrevistados 59 sujeitos, sendo selecionadas dez falas que denotam melhor o todo, sendo cinco dos usuários da ESF e cinco dos trabalhadores da UBS, em sua maioria mulheres, casadas e com idade inferior a 50 anos. A entrevista foi utilizada para complementar e fazer um contraponto com os dados obtidos na prática da assistência e observação.

A análise das informações foi realizada por meio da classificação e sistematização das observações e entrevistas por meio do esgotamento de discursos, buscando identificar as falas mais frequentes e significativas. Em seguida, realizou-se a categorização que emergiu do estudo (MINAYO, 2008). Os dados das observações foram relacionados aos dados da entrevista no sentido de compreender o tema em questão.

O presente trabalho respeitou Resolução no 196/96 do Conselho Nacional de Saúde (BRASIL, 2007). O projeto de pesquisa foi apreciado pelo comitê de ética da Universidade do Extremo Sul Catarinense (UNESC), tendo parecer favorável ( $n^{\circ}$ 254/2005). Para fins de apresentação dos resultados e visando a preservar o anonimato dos participantes, adotamos nomes de frutas para com os entrevistados descritos neste artigo. 
A construção do processo de participação popular e controle social se deu em três momentos: conhecimento situacional, diálogo emancipador e momento " $\mathrm{D}$ ". Para tanto, apresentaremos os resultados obedecendo a essas etapas.

\section{Conhecimento situacional}

O local (território) é um espaço ímpar, que tem suas peculiaridades sociais, culturais, econômicas, entre outras. O município onde a pesquisa aconteceu tem 15 mil habitantes. Colonizado por italianos, o município mantém as tradições de seus antepassados e preserva a religiosidade. As principais fontes econômicas da cidade são a cerâmica de revestimentos, as culturas de fumo, milho e arroz, a criação de suínos e bovinos e a extração de argila para a indústria cerâmica.

A aproximação e o conhecimento da realidade foram fundamentais para o conhecimento e entendimento das demandas da população. Assim, o principal resultado desta etapa foi a criação de um vínculo com os sujeitos do estudo, e reconhecimento das concepções de saúde existentes.

As concepções de saúde foram analisadas nas entrevistas dos sujeitos que possuíam vínculo profissional no serviço de saúde e dos que utilizam os serviços. No primeiro grupo, constatou-se uma influência do "modelo biomédico ou médico hegemônico", intrinsecamente ligado ao conceito da OMS, como expresso nas falas a seguir: "É o bem estar biopsicosocial, ambiental e espiritual". (Tomate); "Saúde é estar bem de corpo e espírito, em todos os sentidos". (Acerola).

Já nas concepções das pessoas que não têm vínculo formal, a saúde apareceu como um conceito mais pluridimensional, ultrapassando em muito a dimensão biológica, apesar de existir, em algumas falas, um vínculo ao modelo biomédico. "É eu tenho pressão alta, mas eu me considero que tenho saúde. Claro que eu tenho que comer pouco sal, mas que eu tenho saúde, eu tenho". (Amora); "Saúde é ser feliz. É poder nos encontrar para rir e brincar". (Laranja).

Esse processo de aproximação nos proporcionou identificação das concepções dos aspectos que norteiam a saúde. Se por um lado identificamos a população ressaltando que o SUS é "o negócio que aposenta a gente [...]. (Caqui)"; pelo lado dos profissionais, ao se referir ao SUS, vislumbramos a centralidade em definiçōes curativistas: "Temos a vigilância, [...] realizamos atendimentos especializados, fizemos suturas, curativos [...]. (Abacate)". 
Desconhecer as ações que o SUS realiza é um grave problema, pois pode repercutir na falta de fiscalização em não saber fiscalizar. Cabe aqui uma reflexão sobre o que os serviços de saúde, ao longo da história, têm passado à população. A cultura criada é o reflexo do próprio modelo, ou seja, centrado no ato médico e voltado, portanto, para açôes curativas.

A falta de conhecimento a respeito da estrutura organizacional do SUS, revelada pela desinformação a respeito da sua recente desarticulação da previdência social, mostra que a formulação da organização dos serviços de saúde, incluindo-se aqui a ESF, não tem tido preocupação na sua base estrutural e funcional para a construção do sujeito, o despertando para a participação e controle social em saúde (FARIA, 1996).

O reconhecimento do território deu-se por meio da prática de caminhadas, conversas com a população dentro e fora da ESF, e imersão nos EPL. Para Acioli (2005, p. 293), "esses espaços se constituem lócus privilegiados de captação e formulação de demandas em saúde por parte da população em geral, sejam elas voltadas para o SUS ou voltadas para outros espaços".

Pôde se perceber que apesar da forte representatividade social em diferentes segmentos, ainda há a carência de um canal participativo voltado diretamente à saúde. "É, nós temos um monte de locais para discutir os problemas da comunidade menos um local voltado para saúde”. (Uva). A partir desta detecção, todos os processos posteriores desta pesquisa caminharam para concretização desta demanda.

\section{Diálogo emancipador}

Esse processo de conhecimento das concepções e aspectos que tangem a saúde e todas suas interfaces foram fundamentados na perspectiva problematizadora de Paulo Freire, ou seja, ao mesmo tempo em que se conhecia a realidade, discutiam-se e problematizavam-se questōes pertinentes à saúde. A perspectiva problematizadora "representa um mecanismo democrático e participativo, tendo uma natureza política, crítica e reflexiva, serve para alimentar circuitos de troca, mediar aprendizagens recíprocas e/ou associar competências" (BRASIL, 2005, p. 8).

Para ilustrar melhor essa proposta, trazemos um exemplo do processo dialógico entre um usuário que queria agendar uma consulta médica e o pesquisador. 
- Não dá. A gente está doente, vai para o posto para ser atendido, tem ainda que marcar número que demora uma semana [...] Então, se é para morrer, a gente morre mesmo, né!, [...] pois quando precisa ser atendido não dá, né! (Pêra).

- Você já conversou com os trabalhadores da ESF? (Pesquisador).

- Não adianta falar. Eles só pensam neles! (Pêra).

- Já pensaram em organizar um grupo para falar com eles? (Pesquisador).

- Não! (Pêra).

- Lembre-se que um grupo de pessoas tem mais força que um sozinho. (Pesquisador).

- É verdade vou levar isto pro conselho de saúde (...). (Pêra).

Dentro dessa lógica libertadora (FREIRE, 1987, 1997), houve um processo de instigação, de mobilização, de sensibilização com todos os atores existentes para se organizarem na luta pelo seu direito à saúde, processo este para o qual a base era o diálogo. Nesse contexto todos são protagonistas do debate, pois se acredita que todos são capacitados em diversas áreas do conhecimento.

O fluxo do pesquisador nos respectivos espaços estava ancorado no preceito de troca de informações, educação em saúde na ótica problematizadora e libertadora e, por conseqüência, na aprendizagem significativa. Ou seja, ao mesmo tempo em que o pesquisador, como profissional estava assistindo os sujeitos que necessitavam dos cuidados de saúde na ESF e EPL, ele também fomentava questôes problematizadoras que tinham como mote a conquista da saúde como direito.

\section{Momento "D"}

Surgiu a partir da visualização do filme Pearl Harbor, quando o General Japonês chama de momento " $\mathrm{D}$ " ou hora " $\mathrm{D}$ " o preciso ataque à base norte americana. Em síntese, foi um encontro com todos os atores envolvidos, dentre estes, autoridades políticas e representantes dos EPL.

Esse encontro foi o momento chave, pois foi desencadeado a partir de várias discussões nos EPL específicos, na prática do cuidado, dentro e fora da ESF, com os profissionais de saúde e gestão. Foram reunidos todos os atores envolvidos para uma grande roda de diálogo, a fim de trocar informações e discutir assuntos da saúde do coletivo para o coletivo. 
Percebeu-se um discreto vínculo do conceito de controle social ao poder fiscalizatório, de maneira individualizada e com o objetivo de sanar problemas próprios que podem ou não representar problemas coletivos: "Eu reclamo mesmo, se eu vou ao postinho e não sou atendida, eu faço o "escambau", ligo pra prefeitura, ligo pra Marconi [rádio regional], não tenho partido e não tenho medo. (Morango)". Mas também, atrelando em algumas afirmações a necessidade da força conjunta para conquista de melhores condições de saúde: "É [...], uma boiada tem mais força que um boi, né! (Melão)”.

Apesar de atribuir o controle social ao exercício fiscalizatório, é fundamental a organização social para que esse seja efetivado. Claro que a fiscalização por si própria é também o exercício do controle social, porém, não se restringe somente a isto. $\mathrm{O}$ resultado desse momento é que, por meio dessa motivação fiscalizatória individual, tem de emergir, antecipadamente, um pensamento grupal de resolução das necessidades também grupais. $\mathrm{O}$ ápice desse momento foi quando um dos atores levantou uma indagação quanto à necessidade de lutar por aquilo que realmente faz sentido para a vida das pessoas.

- Teria nexo fiscalizar algo que incomoda, corrompe ou explora determinadas pessoas, sem que elas realmente evidenciassem que isso é uma injustiça? (Açaí).

E chegaram à conclusão que não há possibilidade de fiscalização sem a disponibilização de informação, indicando a falta de informação como um nó crítico, pois é a partir desta, do diálogo e do pensamento coletivo que esses problemas são discutidos e resolvidos. Não necessariamente há que perpassar um poder de "polícia populacional”, fiscalizando os serviços de saúde. O importante é a conversação com os atores dos processos locais e a pulverização das informaçôes.

A detenção do saber (informações) sem compartilhamento gera poder. Por isto, multiplicar informações sobre a égide da ética e do direito implica compartilhar saberes e poderes (FARIA, 1996, p. 46). Assim, para que a participação na ótica do controle social seja efetiva, um aspecto que tem seu lugar central é a informação, pois "a informação é essencial para o saber local e a participação cidadã” (SCHOELLER, 2003, p. 14).

Essa reunião despertou nas pessoas presentes um sentimento de necessidade de se encontrar pelo menos uma vez por mês para discutir assuntos de interesses coletivos e principalmente socializar informaçōes relacionadas a saúde, tais como: dificuldades da ESF, melhorias no atendimento, propostas de prevenção a saúde entre outras. 


\section{Discussão}

Como resultado da construção deste processo, a população tornou-se mais presente nas decisóes da ESF, mesmo ainda sem ter um espaço participativo local voltado para a saúde. Observamos que a mobilização desencadeada permitiu construir um processo de participação popular e controle social em saúde mesmo sendo uma necessidade local a construção de um EPL voltado para saúde, isso não se deu de maneira instituinte.

Como afirma Acioli (2005, p. 301) acerca da institucionalização:

A participação institucionalizada nos conselhos de saúde é importante, mas não pode nem deve substituir espaços de participação não institucionalizada que se concretizam através de redes de movimentos e grupos sociais, ainda que possam manter entre si uma relação de articulação e fortalecimento. É preciso que o exercício do controle social se dê dentro e fora dos conselhos de saúde.

A institucionalização por si só pode não garantir nada, se não existir anteriormente e durante a construção do processo um diálogo libertador, capaz de motivar as pessoas a lutarem pelos seus direitos de cidadania. Assim, para que se efetivem o controle social e a incorporação da população nesse processo, é preciso lembrar que o lugar da cidadania é onde tudo deve ser visto. É fundamental que ocorra a socialização das informações necessárias à compreensão das várias situaçôes que envolvem as necessidades de saúde de determinada região, para que possam ser pensadas propostas de solução para os problemas identificados.

Durante os três momentos desenvolvidos nesta investigação, partiu-se do princípio que o saber local depende da articulação dos diversos atores sociais e da possibilidade de explicitação das diversas formas de ver o mundo, o cotidiano e os problemas percebidos. Isso significa estar em meio a um jogo de interesses entre usuário e profissionais de saúde, em que o compartilhamento de saberes e a troca de informaçōes são fundamentais.

Como resultado, após o desencadeamento desse processo, entende-se que a participação em saúde só é participação quando esta gira na ótica do controle social. Já o controle social só é efetivado quando por trás dele existe uma população participativa e organizada, que luta pelo cumprimento dos seus direitos e quer ser ator dos processos de transformações sociais.

Os serviços e os profissionais de saúde devem compenetrar de que é também sua responsabilidade fazer circular a informação. Isso implica estar em um "fogo 
cruzado", ou seja, em um jogo de interesses entre o sistema (gestão de saúde e trabalhadores) e os usuários dos serviços de saúde.

Sabe-se que a desinformação é um dos importantes impeditivos para um controle social mais efetivo. É aí que a ideia de controle social como participação cidadã dos atores sociais (gestor, trabalhadores técnicos e assistenciais, prestadores de serviços, representantes dos órgãos de formação e a população) entra em jogo. Implica, necessariamente, abrir-se ao diálogo e isso significa eliminar ou desvincular o processo de trabalho de algumas questôes técnicas, organizacionais, burocráticas, que o sistema exige buscando, como fala Merhy (1997, p. 126) "um outro modo de operar o trabalho em saúde e de construir a relação do trabalhador com os usuários do sistema de atenção à saúde, edificando uma relação mais solidária entre ambos".

O objeto deste estudo, considerando sua complexidade, permitiu a apreensão de elementos que podem interferir na construção da participação e do controle social em saúde. Essa possibilidade foi percebida na medida em que o diálogo foi proposto, conforme a trilha, a caminhada proposta, razão essa pela qual se acredita que esta trajetória será possível, sempre que ao outro seja dado o direito de falar.

O estudo demonstrou que não se pode chegar a um local e querer "bascular" ideias que, segundo determinados teóricos e outros atores, são as mais corretas. Por isso, tem-se a necessidade de aproximação, não só física, mas intelectual. $\mathrm{Ou}$ seja, para início do processo de participação e controle social há a necessidade de se ter um sincronismo com todos os atores envolvidos nas questôes que tangem a luta pela conquista do direito à saúde.

O diálogo de que falamos significa criar condições para a explicitação das ideias, dos problemas, do embate democrático. Para isso, é preciso que a política de saúde atenda com propriedade técnica e ética as necessidades dos atores sociais, especialmente a quem se dirige (os usuários), mas não se esquecendo de proporcionar condições aos trabalhadores para a produção dos cuidados em saúde e o atendimento das necessidades da população.

O diálogo também se propõe romper com fronteiras do Sistema (centralidade burocrática) e imergir na conversação com os sujeitos, entender os porquês da população, ser como uma roda para um automóvel, que não sai do lugar, mas leva a lugares inimagináveis (colocando esta analogia em seu devido lugar, percebe-se que deve haver interação e conhecimento entre a roda/carro/condutor). O estudo 
demonstrou também que, abrindo as possibilidades para o "sentar juntos", trocar informações, compartilhar saberes, a população participa e busca apropriar-se das discussóes (como o que ocorreu), embora possa ter sido uma quebra das regras no cotidiano da ESF.

Mas, para que se possa melhor entender e refletir sobre como agir no sentido do diálogo e, consequentemente, na efetivação da participação popular e controle social, é preciso rever e reavaliar os papéis que se desempenha; os conceitos que se constrói; as organizações das quais se participa; os atos que se pratica. Afinal, é pela caminhada junto aos atores sociais e entre os diversos caminhos que se constroem possibilidades de mudanças.

\section{Considerações finais}

O arcabouço metodológico neste tipo de estudo foi fundamental para o alcance dos objetivos. Discutir participação popular e controle social não é tarefa fácil, quanto mais desenvolver um processo de construção. Pode-se dizer que é "remar contra a maré", no sentido de ir contra modos hegemônicos de pensar e produzir saúde.

Entendemos esse processo como algo permanente, portanto, não se finda com o término deste estudo, mas abre espaços para reflexões de outras formas de construção e consolidação dos princípios e diretrizes que norteiam o SUS, uma vez que a proposta desta pesquisa não era esgotar todas as facetas que cercam tal temática.

O mais importante de todo este estudo foi perceber que é possível desencadear um processo de participação popular e controle social em saúde, ainda que incipiente, em um microterritório de atuação, garantindo assim um Sistema Único de Saúde mais ético e equânime.

\section{Referências}

ACIOLI, S. Participação social na saúde: revisitando sentidos, reafirmando propostas. In: PINHEIRO, R.; MATOS, R. A. Construção social da demanda: direito à saúde, trabalho em equipe, participação e espaço público. In: Rio de Janeiro: Cepesc, 2005. p. 293-301.

BARROS, E. Controle social e o processo de descentralização dos serviços de saúde. In: BRASIL. Ministério da Saúde. Incentivo à participação popular e o controle social no SUS: textos técnicos para conselheiros de saúde. Brasília: IEC, 1994. p. 35-36. 
BECK, C.T.; HUNGLER, B.P.; POLIT, D.F. Fundamentos de pesquisa em enfermagem.

Métodos, avaliação e utilização. 5.ed. Porto Alegre: Artmed, 2004. 488 p.

BRANDÃO, C.R. (Org.). Pesquisa participante. 8.ed. São Paulo: Brasiliense, 1999. 212p.

BRASIL. Ministério da Saúde. Secretaria de Gestão e Investimento na Saúde. Departamento de Gerenciamento de Investimentos. Guia do Conselheiro: Curso de Capacitação de Conselheiros Estaduais e Municipais de Saúde. Brasília: Ministério da Saúde, 2002. p. 51.

. Secretaria de Gestão do Trabalho e da Educação na Saúde. Departamento de Gestão da Educação na Saúde. A educação permanente entra na roda: polos de educação permanente em saúde, conceitos e caminhos a percorrer. 2.ed. Brasília: Ministério da Saúde, 2005. p. 8.

- Secretária de Gestão do Trabalho e da Educação em Saúde. Departamento de Gestão da Educação na Saúde. Curso de formação de facilitadores de educação permanente em saúde. Unidade de aprendizagem trabalho e relaçôes na produção do cuidado. Rio de Janeiro: Fiocruz, 2005. p. 54.

. Conselho Nacional de Saúde. Resolução no 196 de 10 de outubro de 1996. Diretrizes e normas regulamentadoras de pesquisa envolvendo seres humanos. Disponível em: http://conselho.saude.gov.br/resolucoes/1996/Reso196.doc. Acesso em: 15 set. 2007.

CORTES, S.M.V. Construindo a possibilidade da participação dos usuários: conselhos e conferências no Sistema Único de Saúde. Sociologias. Porto Alegre, n. 7, jun. 2002.

DESLANDES, S.F.; GOMES, R. A pesquisa qualitativa nos serviços de saúde: notas teóricas. In: BOSI, M.L.M.; MERCADO, F.J. (Org.). Pesquisa qualitativa de serviços de saúde. Petrópolis: Vozes, 2004. p. 101.

DORNELLES, S.; LOCKS, M.T. Controle social: de quem? Para o quê? Saúde em debate. Rio de Janeiro, v. 27, n. 65, p. 348-357, 2003.

FARIA, E.M. Comunicação na Saúde: fim da simetria? Pelotas: Ed. Universitária, 1996. 175 p. FREIRE, P. Pedagogia da autonomia. São Paulo: Paz e Terra, 1997.

. Pedagogia do oprimido. Rio de Janeiro: Paz e Terra, 1987.

MERHY, E.E. O SUS e um dos seus dilemas: mudar a gestão e a lógica do processo de trabalho em saúde. Um ensaio sobre a micropolítica do trabalho vivo. In: FLEURY, S. (Org.). Saúde e democracia: a luta do CEBES. São Paulo: Lemos Editorial, 1997, p. 125-141.

MERHY, E.E. et al. O trabalho em saúde: olhando e experienciando o SUS no cotidiano São Paulo: Hucitec. 2.ed., 2004. 296 p.

MINAYO, M.C.S. O desafio do conhecimento: pesquisa qualitativa em saúde. 6.ed. São Paulo Hucitec, 1999. 269 p.

. Pesquisa social. Teoria, método, criatividade. 27.ed. Petrópolis: Vozes, 2008. 110 p.

PERNA, P.O. O controle social na ponta do SUS: o caso de Pontal do Sul - Município de Pontal 
1242 do Paraná - PR. 2000. 130 p. Dissertação (Mestrado em Assistência de Enfermagem) - Centro de Ciências da Saúde. Universidade Federal de Santa Catarina, Florianópolis, 2000.

SCHOELLER, S.D. Proposta para educação permanente em tecnologias de planejamento participativo em saúde. Material técnico. Criciúma: Polo de Educação Permanente para os Trabalhadores do SUS, 2003. p. 14.

SILVA, E.L.; MENEZES, E.M. Metodologia da pesquisa e elaboração de dissertação. 3.ed. Florianópolis:UFSC, 2001.

TOBAR, F.; YALOUR, M.R. Como fazer teses em saúde pública. Conselhos e ideias para projetos e redigir teses e informes de pesquisas. Rio de Janeiro: Fiocruz, 2001. p. 48.

\section{Nota}

${ }^{1} \mathrm{O}$ presente artigo é uma ampliação teórica do trabalho contemplado como menção honrosa na categoria trabalhos acadêmicos, na segunda edição do Prêmio Sérgio Arouca de Gestão Estratégica e Participativa no ano de 2007, que foi publicado em 2008. 


\section{Abstract}

Citizen participation and social control in health: challenges of the family health team

Social control in Brazil has come through a process of social struggle, specially starting with the social movements. A qualitative study with the technique of action research was developed, aiming at building a popular participation and social control process within a Family Health Team in the south of Santa Catarina State, Brazil. The subjects of the study were the population who attended the healthcare service, participating or not in the organized social movements, and the health workers. Data collection comprised participant observation and interviews. The construction of citizen participation and social control process was developed in three moments: awareness of the situation, independent dialogue and " $\mathrm{D}$ " moment. The study presents alternatives for this process. In this case, dialogue was the essential instrument to encourage and search of other ways for the Unified Health System.

> Key words: Consumer's participation; citizen participation; social control policies; primary healthcare; Unified Health System; right to health. 